Berkers, Pauwke, Susanne Janssen \& Marc Verboord. 2009. 'Contra-flows in de literaire journalistiek? Een vergelijkende analyse van de aandacht voor niet-Westerse schrijvers uit binnen- en buitenland in Amerikaans, Duitse, Franse en Nederlandse dagbladen, 1955-2005. Nederlandse Letterkunde 14(2):77-103 http://www.ingentaconnect.com/content/aup/nl/2009/00000014/00000002/art00001

\title{
'Contraflows' in de literaire journalistiek? Een vergelijkende analyse van de aandacht voor niet-westerse schrijvers uit binnen- en buitenland in Franse,
} Duitse, Nederlandse en Amerikaanse dagbladen, 1955-2005

Pauwke Berkers (berkers@eshcc.eur.nl)

Department of Art and Culture Studies (ESHCC), Erasmus University Rotterdam, the Netherlands

\section{Susanne Janssen}

Marc Verboord

\begin{abstract}
In contrast to most studies on cultural globalization, this article examines the dynamics of crosscultural exchange between and within (western) nation-states. Through content analysis, we examine the extent and composition of the newspaper coverage given to literary authors of non-western ethnic origin - both foreign and domestic - in France, Germany, the Netherlands, and the United States between 1955 and 2005. Newspaper attention to ethnic minority authors appears to be related to the size of the ethnic minority population, their language proficiency and educational background and the extent to which key institutions in the national literary field are receptive to ethnic diversity, leading to extensive coverage in the U.S. and limited attention in Germany. Newspapers in countries that hold a central position in the literary world-system (United States) appear to be more strongly focused on domestic ethnic minority authors, whereas newspapers in less central countries cover more foreign authors originating in non-western countries, particularly when they have strong geo-linguistic ties with these countries (France). Finally, our results indicate that U.S. ethnic minority authors first gained recognition within the national literary field, and later on, through the centrality of the United States in the literary world-system, also acquired international literary prestige.
\end{abstract}




\section{INLEIDING}

Globalisering behoort tot de populairste onderwerpen in de sociale wetenschappen, ook al ontbreekt er een consistente definitie van het fenomeen (Fiss en Hirsch 2005; Hargittai en Centeno 2001). Guillén (2001:236) integreert een aantal definities in zijn omschrijving van globalisering als een "process leading to greater interdependence and mutual awareness (reflexivity) among economic, political, and social units in the world, and among actors in general". Onderzoekers die zich op culturele globalisering richten, hanteren meestal een wat nauwere opvatting van het begrip en bestuderen vooral de transnationale verspreiding van westerse populaire cultuur (Crane 2002; Kaufman en Patterson 2005). De belangrijkste theoretische vertrekpunten benadrukken ofwel de culturele "homogenisering" door het imperialisme van westerse multinationals, ofwel het vermogen van locale actoren om de mondiale culturele producten een hybride culturele vorm te geven (Darling-Wolf 2008; Kraidy 2002; Lizardo 2008). Een aantal aspecten in het onderzoek naar culturele globalisering blijft bijgevolg onderbelicht: (i) de toename van de verspreiding van culturele artefacten van niet-westerse oorsprong in de westerse wereld, (ii) de institutionele erkenning, van zulke artefacten binnen westerse natiestaten en (iii) de rol van internationale migratie in dit verband.

Dit artikel belicht deze aspecten door middel van een vergelijkende analyse van de hoeveelheid en aard van de dagbladberichtgeving over literaire auteurs met een niet-westerse achtergrond $^{1}$ in Frankrijk, Duitsland, Nederland en de Verenigde Staten, tussen 1955 en 2005. Postkoloniale literatuurwetenschappers signaleren een aanzienlijke "contraflow" vanuit "the Rest" richting "the West," waardoor het literaire aanbod in westerse landen een grotere etnische diversiteit zou vertonen (Huggan 2001). Bovendien heeft internationale migratie - één van de meest alomtegenwoordige vormen van globalisering (Held, McGrew, Goldblatt en Perraton 1999) - geleid tot een toename van etnische minderheidsauteurs in deze landen, met als gevolg dat er in westerse natiestaten een groeiend besef van de etnische "ander" is ontstaan. Als zodanig analyseren we de

\footnotetext{
${ }^{1}$ Om redenen van crossnationale vergelijkbaarheid en conceptuele helderheid, gebruiken we de metacategorie "niet-westers" ter aanduiding van zowel binnenlandse etnische minderheidsauteurs als buitenlandse etnische minderheidschrijvers en niet-westerse meerderheidsauteurs. De details zijn te vinden in de Data en Methoden paragraaf.
} 
dynamiek van crossculturele uitwisselingen niet alleen tussen maar ook binnen westerse natiestaten, waarbij we de berichtgeving over zowel buitenlandse als binnenlandse literaire auteurs van nietwesterse oorsprong betrekken.

De berichtgeving over niet-westerse literatuur in westerse kwaliteitskranten vormt een belangrijke indicator voor de institutionele erkenning van auteurs met een niet-westerse achtergrond. Wat sociaal en cultureel relevant geacht wordt, hangt in hoge mate af van de selecties die deze kranten maken (Benson en Saguy 2005; Ferree, Gamson, Gerhards en Rucht 2002; Shoemaker en Reese 1996). Kwaliteitskranten spelen eveneens een centrale rol in het proces van erkenning en consecratie van culturele artefacten, omdat ze met hun keuzes en oordelen de perceptie en waardering van het publiek en van andere actoren in het culturele veld sturen en vormgeven (Bourdieu 1993; Van Rees 1983). Met behulp van een inhoudsanalyse van de dagbladberichtgeving over niet-westerse schrijvers valt daarom na te gaan in hoeverre het toegenomen bewustzijn van de etnische 'ander' zich heeft vertaald in institutionele erkenning in een bepaalde samenleving. Duitsland, Frankrijk, Nederland en de VS zijn in deze studie opgenomen om een vergelijking te kunnen trekken tussen de journalistieke belangstelling voor niet-westerse auteurs in traditionele immigratielanden (de VS), voormalige koloniale machten (Frankrijk, Nederland) en arbeidsmigratielanden (Duitsland).

De institutionele erkenning van binnenlandse (Berkers 2009; Duell 2000) en buitenlandse auteurs van niet-westerse oorsprong (Griswold 1987; 1992) lijkt deels samen te hangen met dezelfde macrostructurele processen (dekolonisatie en internationale migratie). De laatste categorie auteurs heeft echter vaak al literaire erkenning in eigen land en/of in een van de grote, internationale literaire centra verworven (Casanova 2004; Malingret 2002; Steenmeijer 1989), terwijl de waardering van etnische minderheidsauteurs vaker verband lijkt te houden met kwesties zoals integratie en de verhouding tot het binnenlandse literaire veld. Voorafgaand aan de presentatie van onze onderzoeksopzet en resultaten, bespreken we hierna eerst de verschillende macrostructurele en veldfactoren die van invloed kunnen zijn op de berichtgeving over beide categorieën auteurs in de onderzochte landen. 


\section{THEORETISCHE ACHTERGROND}

\section{Berichtgeving over (niet-westerse) binnenlandse etnische minderheidsauteurs}

Dagbladberichtgeving over binnenlandse auteurs met een niet-westerse achtergrond zal waarschijnlijk per land variëren, afhankelijk van de kenmerken van minderheidsgroepen in elk afzonderlijk land en de mate van erkenning van etnische minderheidsauteurs binnen het literaire veld.

\section{Etnische minderheidsgroepen}

Bij ontstentenis van betrouwbare longitudinale gegevens over de populatie van etnische minderheidsauteurs in elk land, ${ }^{2}$ bekijken we eerst de grootte van de totale etnische minderheidspopulatie in elk land (Tabel 1) aangezien deze rudimentaire factor mogelijk ten grondslag ligt aan crossnationale verschillen in de aanwezigheid van etnische minderheidsauteurs in deze landen. In de VS vertegenwoordigen etnisch-raciale minderheden ongeveer een vijfde (1975) tot een derde (2005) van de bevolking, een veelvoud van het aandeel niet-westerse minderheden in Nederland. Turken vormen verreweg de grootste etnische minderheidsgroep in Duitsland. Longitudinale gegevens over andere niet-westerse groepen zijn niet beschikbaar. Daarom gebruiken we de Turkse minderheid - het totaal van buitenlanders en jaarlijkse naturalisaties - als een benadering voor de hele nietwesterse minderheidsgroep in Duitsland. De Franse regering maakt, net als de Duitse overigens, geen onderscheid tussen meerderheids- en minderheidsgroepen en verzamelt alleen data over niet genaturaliseerde bevolkingsgroepen. Het aandeel niet-westerse buitenlanders bedraagt in 1999 meer dan 3\%, maar zou waarschijnlijk tweemaal zo groot zijn geweest als de genaturaliseerde nakomelingen van twintigste-eeuwse immigranten meegeteld waren (Fetzer en Soper 2005).

\footnotetext{
${ }^{2}$ Er bestaan wel enkele impressionistische overzichten die - hoewel niet bruikbaar als indicator voor de gehele populatie van etnische minderheidsauteurs - in ieder geval laten zien dat dergelijke auteurs niet alleen aanwezig zijn in het Amerikaanse literaire veld, maar ook in de door ons onderzochte Europese landen. Zo telt Rösch (2006) 25 Turkse minderheidsauteurs die tenminste één boek hebben gepubliceerd in 2006. Nap-Kolhoff (2002) en Aynan (2006) schatten de populatie Marokkaanse en Turkse minderheidsauteurs in Nederland op respectievelijk 21 en 20. In Frankrijk waren in 1997 tenminste 34 Noord Afrikaanse minderheidsschrijvers actief (Hargreaves 1997).
} 
[Tabel 1 ongeveer hier]

Deze getallen alleen geven echter - in het gunstigste geval - slechts een grove indicatie van de mate van aanwezigheid van etnische minderheidsauteurs. De literaire velden van westerse samenlevingen zijn notoir selectief als het aankomt op sociale achtergrond, opleiding en taalbeheersing. Het vergt nogal wat cultureel en linguïstisch kapitaal (Bourdieu 1993) om literair auteur te worden, dat wil zeggen om als zodanig door literaire uitgevers en andere relevante actoren in het literaire veld erkend te worden. Aspirant-schrijvers uit de lagere sociaal-economische klassen met een laag opleidingsniveau zullen daarom minder gemakkelijk toegang hebben tot het literaire veld; en dit geldt a fortiori indien hun beheersing van de landstaal onvoldoende is. ${ }^{3}$

In Frankrijk kunnen immigranten relatief eenvoudig de Franse nationaliteit verwerven waardoor zij, officieel althans, snel deel worden van de Franse samenleving als geheel. Mensen uit de Mahgreb hebben een goede beheersing van de Franse taal, vooral de Algerijnse gemeenschap, maar zij zijn nog steeds oververtegenwoordigd in de lager opgeleide, sociale strata (Hargreaves 1995). De Turkse minderheid in Duitsland beheerst het Duits veel minder goed en is lager opgeleid dan andere etnische minderheidsgroepen (Dustmann 1994; Diehl en Blohm 2003; Worbs 2003). ${ }^{4}$ Voor Nederland geldt dat de taalbeheersing en het opleidingsniveau van immigranten (en hun nakomelingen) uit de voormalige Nederlandse koloniën niet heel ver achterlopen op die van de Nederlandse meerderheid, in tegenstelling tot die van de Turkse en Marokkaanse minderheidsgroepen (Tesser, Merens en van Praag 1999). De collectieve identiteit van de Amerikaanse natie wordt gedragen door homogeniteit in taal, wat concreet betekent dat etnische minderheidsgroepen zich daar de nieuwe taal veel eerder eigen maken dan in andere landen (Portes en Rumbaut 1996). Toch zijn er qua Engelse taalbeheersing grote

\footnotetext{
${ }^{3}$ Wanneer en in welke mate verschillende etnische minderheidsgroepen in elk land de taal van het gastland meester worden, hangt samen met een complex samenspel van bestemming, oorsprong en omgeving (van Tubergen en Kalmijn 2005), zoals opvattingen over burgerschap in het land van bestemming, de ideologische grondslag (universalisme, assimilatie of pluralisme) van het immigratie- en taalbeleid (Brubaker 1992; Koopmans, Statham, Giugni en Passy 2005), de sociaal-economische kenmerken van het land van oorsprong (Massey, Arango, Hugo, Kouaouci, Pellegrino en Taylor 1993) en de linguïstische afstand tussen land van herkomst en bestemming (Espenshade en Fu 1997; Chiswick en Miller 2001). Deze overwegingen vallen echter buiten het bereik van deze studie.

${ }^{4}$ De oorzaak hiervan ligt misschien in de taalafstand tussen het Duits en het Turks en de tendens, in de Turkse gemeenschap, om in Turkse enclaves te wonen, met een relatief lage blootstelling aan het Duits als gevolg (ibid.)
} 
verschillen tussen de etnisch-raciale bevolkingsgroepen. Hispanics - vooral Mexican-Americans lopen achter op de andere minderheidsgroepen (Carliner 2000). ${ }^{5}$ Deze groep is gemiddeld ook het laagst opgeleid, gevolgd door de African-American minderheid.

De gegevens over etnische minderheidsgroepen en hun taalbeheersing en opleidingsniveau doen vermoeden dat de Verenigde Staten relatief meer etnische minderheidsauteurs telt dan de drie Europese landen - en daarmee dat Amerikaanse dagbladen verhoudingsbewijs meer aandacht aan dergelijke auteurs besteden dan hun tegenhangers in onderzochte Europese landen. Duitsland vormt in dit verband vermoedelijk de hekkensluiter, terwijl Frankrijk en Nederland een tussenpositie innemen.

\section{Institutionele erkenning en het literaire veld}

Louter de aanwezigheid van etnische minderheidsauteurs leidt echter niet automatisch tot berichtgeving over deze auteurs in de dagbladen. Journalistieke belangstelling hangt ook samen met de machtsrelaties in het literaire veld van een land, waar verschillende groepen specifieke opvattingen over literatuur voorstellen, steunen en betwisten als een manier om - vaak onbewust - hun eigen positie te markeren en versterken (Bourdieu 1993). De uitkomst van deze strijd bepaalt, onder andere, welke auteurs institutionele erkenning verkrijgen en welke criteria geldig geacht worden om hun werk te categoriseren. De hoeveelheid belangstelling voor etnische minderheidsauteurs in de dagbladen lijkt daarom sterk afhankelijk van de mate waarin etnische diversiteit weerklank vindt in de nationale literaire velden. Journalistieke critici plegen zich in hun selectie van te bespreken werken in hoge mate te laten leiden door de selecties en oordelen van collega critici en van andere (institutionele) connaisseurs in het literaire veld (Dorleijn en Van Rees 2006; Janssen 1997; Van Rees 1987). De mate waarin gezaghebbende instituties in het literaire veld - zoals literatuurgeschiedenissen, literatuurfondsen en literaire prijzen - oog hebben voor etnische diversiteit is waarschijnlijk een goede predictor voor de mate van dagbladaandacht voor etnische minderheidschrijvers.

Etnische diversiteit is sinds de burgerrechtenbeweging een belangrijk punt in het Amerikaanse literaire veld. De eerste studieprogramma's en afdelingen in African-American studies werden aan het

\footnotetext{
${ }^{5}$ Dit komt waarschijnlijk doordat Mexico aan Amerika grenst, waardoor arbeidskrachten die het Engels niet beheersen toch gemakkelijk naar de VS emigreren (ibid.).
} 
eind van de jaren '60 in de vorige eeuw geïnitieerd, waarna andere, weliswaar minder succesrijke “groepsstudies" volgden, zoals Latino, Native-American en Asian-American studies (Duell 2000). Deze ontwikkelingen leidden in de jaren tachtig en negentig tot een heftige tegenreactie van de conservatieve academische elite. Deze canon wars hadden echter een tegengesteld effect, namelijk een toename van etnische minderheidsauteurs en andere "buitengesloten" groepen in de canon (Bryson 2005; Corse en Griffin 1997). In samenhang met deze ontwikkelingen laten Amerikaanse literaire anthologieën en wetenschappelijke tijdschriften over literatuur een forse toename zien in de vertegenwoordiging van etnische minderheidsauteurs (Berkers 2009). Andere literaire instituties lijken echter minder ontvankelijk te zijn voor etnische diversiteit. Subsidie voor etnische minderheidsauteurs door de National Endowment for the Arts is in de loop van de tijd zelfs enigszins teruggelopen (Berkers 2009), terwijl aan maar weinig etnische minderheidsauteurs een prestigieuze literatuurprijs is toegekend. ${ }^{6}$

In Frankrijk worden VS-achtige "groepsstudies" niet legitiem geacht (Duell 2000). Het Franse idee van universalisme impliceert dat er geen reden zou zijn om de literaire canon open te breken; de principes van meritocratie en gelijkheid zouden ervoor zorgen dat iedere auteur - of het nu een minderheidsauteur is of niet - dezelfde kans heeft om in de canon opgenomen te worden. Een aantal in Frankrijk woonachtige auteurs van niet-westerse oorsprong heeft inderdaad in de jaren ' 80 en '90 prestigieuze nationale literatuurprijzen gewonnen, zoals Tahar Ben Jelloun (Prix Concourt 1987), Amin Malouf (Prix Concourt 1993) en Patrick Chamoiseau (Prix Concourt 1995), maar door de bank genomen lijkt het Franse literaire veld niet erg open te staan voor etnische minderheidsauteurs.

De letterkundige afdelingen van Duitse universiteiten hebben weinig affiniteit met het multiculturalisme, voor zover zij zich er al niet ronduit tegen verzetten (Jankowsky 1997; Teraoka 1997). Het werk van etnische minderheidschrijvers is in Duitsland dan ook geen deel gaan uitmaken van de literaire canon. Etnische minderheidsauteurs ontbreken vrijwel geheel in de literatuurgeschiedenissen en worden ook in de literaire tijdschriften nauwelijks genoemd (Berkers 2009). In 2006 werden ongeveer 400 auteurs door het Duitse fonds voor de letteren (Deutscher

\footnotetext{
${ }^{6}$ Tussen 1955 en 2005 is de Pulitzer Prize voor Fictie en de National Book Award voor Fictie respectievelijk zeven en drie keer toegekend aan een etnische minderheidsauteur.
} 
Literaturfonds) financieel gesteund; slechts twee daarvan hadden een Turkse achtergrond: Emine Sevgi Özadamar en Feridun Zaimoglu (Berkers 2009). Deze twee auteurs zijn ook de enige minderheidsschrijvers die prestigieuze literatuurprijzen gewonnen hebben.

In Nederland is er wel discussie geweest over de literaire canon, maar die was niet erg fel (Joosten 2005). De opname van etnische minderheidsauteurs in literatuurgeschiedenissen begon eerder dan in Duitsland, namelijk eind jaren '80, maar hun aandeel kroop slechts langzaam omhoog tot circa 4\% in 2006 (Berkers 2009). Belangrijke instellingen voor subsidie van literatuur, zoals het Fonds voor de Letteren, hebben etnische minderheidsauteurs echter expliciet in hun beleid opgenomen door bijvoorbeeld speciale programma's voor deze auteurs te creëren. Het aandeel etnische minderheidsauteurs dat door dit fonds wordt gesteund bedroeg $1 \%$ in 1970 en steeg tot $7 \%$ in 2005 (Berkers 2009). De laatste jaren hebben verscheidene etnische minderheidsauteurs prestigieuze nationale literatuurprijzen gewonnen, zoals Abdelkader Benali (Libris prijs 2003) en Mustafa Stitou (VSB poëzieprijs 2004).

De gegevens over de resonantie van etnische diversiteit binnen het literaire veld van elk land doen vermoeden dat de Amerikaanse dagbladen relatief de meeste aandacht zullen besteden aan etnische minderheidsauteurs, gevolgd door Nederland, terwijl de dagbladaandacht in Frankrijk en Duitsland het geringst zal zijn.

\section{Berichtgeving over buitenlandse auteurs van niet-westerse oorsprong}

De hoeveelheid en aard van dagbladberichtgeving die buitenlandse literaire auteurs van niet-westerse oorsprong ten deel valt, varieert vermoedelijk van land tot land, afhankelijk van de positie die deze auteurs in het literair wereldsysteem innemen en van de geo-linguïstische banden die een land heeft met niet-westerse landen.

\section{Literair wereldsysteem}

Culturele globalisering heeft ertoe geleid dat nationale literaire velden zijn opgenomen in transnationale systemen van uitwisseling, invloed en competitie. Als gevolg hiervan is een "literair wereldsysteem" ontstaan (De Swaan 1995; Heilbron 1999), wat inhoudt dat er een impliciete rangorde 
ontstaat voor landen, naargelang het vermeende belang van hun literaire productie. Een centrale positie in dit literair wereldsysteem zal waarschijnlijk zijn weerslag vinden in het aandachtsniveau in de dagbladberichtgeving die internationale auteurs van niet-westerse oorsprong ten deel valt (Janssen 2009): hoe centraler de positie van een land, (i) des te groter de aandacht die kranten aan binnenlandse, in plaats van buitenlandse (inclusief niet-westerse) auteurs zullen schenken; (ii) des te waarschijnlijker de etnische minderheidsauteurs van het betreffende land aandacht zullen krijgen in de buitenlandse bladen; en (iii) des te hoger het aantal (niet-westerse) in dat land gevestigde auteurs waarover bericht wordt.

In 1955 nam de VS al een prominente internationale positie in, wat vooral te danken was aan hun aandeel in de productie van populaire fictie, maar de leidende rol werd gedeeld met Frankrijk, een land dat in de meeste culturele velden een zeer centrale rol speelde (Janssen, Kuipers en Verboord 2008), ook in het literaire. Sinds die tijd is de positie van de VS alleen maar prominenter geworden in het veld van zowel 'populaire' als 'serieuze' literatuur, wat samenvalt met de toenemende suprematie van de Engelse taal en de Amerikaanse cultuur. De positie van Frankrijk is in diezelfde periode juist minder dominant geworden (Janssen 2009; Sapiro 2008), hoewel het land voor West- en NoordAfrikaanse auteurs alsook voor Franstalige auteurs in België, Zwitserland en Canada nog steeds het middelpunt vormt (Casanova 2004). Duitsland is er sinds WOII niet in geslaagd om een centrale positie te (her)winnen buiten het Duitstalige gebied (Sassoon 2006), terwijl Nederland traditioneel een (semi)perifere positie inneemt (Heilbron 2008).

De theorie van het literair wereldsysteem suggereert derhalve dat hoe meer perifeer de positie van een land is, des te meer aandacht er zal worden gegeven aan internationale auteurs in de dagbladen. Concreet betekent dit dat deze theorie voorziet dat Nederlandse en Duitse dagbladen de meeste aandacht zullen schenken aan buitenlandse auteurs met een niet-westerse achtergrond, gevolgd door dagbladen in Frankrijk en de VS.

\section{Geo-linguïstische banden}

Uit onderzoek naar culturele globalisering en de productie van internationaal nieuws blijkt dat over het algemeen geografische nabijheid en taalverwantschap belangrijke voorspellers zijn van de mate van 
ontvankelijkheid voor internationale producten of gebeurtenissen (La Palestina en Straubhaar 2005; Clausen 2003). Hoe sterker de geo-linguïstische banden tussen een land en bepaalde niet-westerse landen, des te meer aandacht waarschijnlijk wordt geschonken aan auteurs met een achtergrond in die landen. De stevigste geo-linguïstische band wordt waarschijnlijk gevormd door een gedeelde nationale identiteit, met dezelfde taal en (koloniale) geschiedenis, gevolgd door alleen een talige band, terwijl banden die enkel stoelen op geografische nabijheid waarschijnlijk het zwakst zullen zijn.

\section{[ Tabel 2 ongeveer hier]}

Tabel 2 toont voor elk land de belangrijkste geo-linguïstische banden met niet-westerse landen. Frankrijk was ooit het centrum van een van de belangrijkste koloniale grootmachten ter wereld. In veel Franse koloniën was het Frans de officiële taal en bleef het zelfs na de onafhankelijkheid een belangrijke taal (De Swaan 2001). Het koloniale rijk van Nederland was een stuk kleiner en hoewel het Nederlands nu nog steeds de officiële taal is in Suriname en de Nederlandse Antillen, is Nederland nooit het centrum geweest van een internationale gemeenschap van Nederlandssprekende landen.

Frankrijk, Duitsland en Nederland hebben nauwelijks louter op taal gebaseerde banden met niet-westerse landen. ${ }^{7}$ De Verenigde Staten echter deelt de taal met veel voormalige Britse koloniën (zie Tabel 2). Nog belangrijker is het feit dat, sinds 1945, het Engels in grote delen van de wereld andere talen - vooral het Frans - als dominante of tweede taal heeft verdreven (Crystal 1997). De VS heeft bovendien nauwe banden met andere Engelsprekende landen, vooral met het Verenigd Koninkrijk, Canada en Australië, landen die alle drie veel niet-westerse immigranten hebben.

Een derde categorie vormen de banden verkregen door arbeidsmigratie. Veel West-Europese landen begonnen na 1945 met de rekrutering van arbeiders uit andere landen; in eerste instantie dichtbij, uit landen aan de Middellandse zee (Italië, Spanje, Griekenland); later ook uit landen die geografisch en cultureel verder weg lagen. Frankrijk heeft zijn gastarbeiders vooral uit de voormalige (Franssprekende) Afrikaanse koloniën gehaald (Fetzer 2000), terwijl de meeste immigranten in

\footnotetext{
${ }^{7}$ Een aantal niet-westerse landen heeft een Franssprekende minderheid die tot de culturele en literaire elite van deze landen behoort.
} 
Duitsland en Nederland afkomstig zijn uit landen die in linguïstisch opzicht ver verwijderd zijn van het gastland, zoals Turkije en Marokko (Lucassen en Penninx 1996; Martin 1998). De meeste arbeidmigranten in de VS komen uit Mexico en hebben Spaans als moedertaal (Portes en Rumbaut 1996).

De aard van de geo-linguïstische banden die elk land met niet-westerse naties heeft, doet vermoeden dat Franse en Nederlandse dagbladen de meeste aandacht aan buitenlandse auteurs met een niet-westerse achtergrond zullen geven en daarbij vooral gericht zijn op Frans- of Nederlandssprekende auteurs uit de voormalige koloniën. De dagbladen in de VS en Duitsland zullen waarschijnlijk minder over buitenlandse niet-westerse auteurs berichten en daarbij vooral gericht zijn op Engelstalige auteurs, zonder een specifieke groep eruit te lichten.

\section{DATA EN METHODEN}

\section{Inhoudsanalyse}

Frankrijk, Duitsland, Nederland en de Verenigde Staten zijn in dit onderzoek opgenomen omdat deze landen in veel opzichten op elkaar lijken (het zijn allemaal moderne welvaartsmaatschappijen), maar tevens voldoende differentiatie vertonen op de verschillende relevante dimensies, zoals etnische diversiteit; koloniale geschiedenis en immigratiegeschiedenis; en de positie in het literair wereldsysteem.

Voor elk land hebben wij een inhoudsanalyse uitgevoerd op de twee belangrijkste kwaliteitskranten (één voor de VS) die in de respectieve landen gelden als dagbladen die voor een breed scala aan onderwerpen, waaronder literatuur, de toon zetten voor nieuwsberichtgeving, opiniering en het vormen van waardeoordelen (Janssen e.a. 2008): Le Monde, Le Figaro (Frankrijk), Frankfurter Allgemeine Zeitung, Süddeutsche Zeitung (Duitsland), NRC Handelsblad, de Volkskrant (Nederland) en de New York Times (VS).

Voor elk dagblad hebben we een steekproef uit de berichtgeving over literatuur geanalyseerd in 1955, 1975, 1995 en 2005. Met behulp van de methode van de 'geconstrueerde week' (Riffe, Lacy en Aust 1993) hebben we voor elke krant per ijkjaar 24 edities geselecteerd ( 28 in het geval van de 
New York Times). Per editie hebben we alle artikelen over literatuur in aanmerking genomen: recensies, nieuwsrapportages, interviews, etcetera, etcetera, over zowel literaire proza en poëzie als populaire genres. Elk artikel is gecodeerd voor, onder andere, de naam en nationaliteit van de actor die het meest prominent in het artikel figureerde. Voor de huidige analyse hebben we alle artikelen geselecteerd $(\mathrm{N}=2300)$ die gericht zijn op een specifieke literaire auteur of groep auteurs.

\section{Operationalisering van nationaliteit, etnische achtergronden geo-lingü̈stische banden}

Als eerste hebben we schrijvers wat betreft 'nationaliteit' gecodeerd, omdat we immers twee typen niet-westerse auteurs vergelijken, binnenlandse en buitenlandse. Als het niet bekend was welke nationaliteit een auteur had, gebruikten we het land van herkomst van de schrijver zoals dat in literaire naslagwerken werd vermeld

Om redenen van crossnationale vergelijkbaarheid en conceptuele helderheid, hanteren we de metacategorie "schrijvers met een niet-westerse etnische achtergrond." In navolging van Nagel (1994:153) beschouwen we etniciteit als "constructed out of the material of language, religion, culture appearance, ancestry or regionality." Wij operationaliseren "een niet-westerse etnische achtergrond" dan ook in termen van nationale of regionale oorsprong, namelijk landen of regio's waarvan de dominante cultuur niet voortkomt uit de Joods-christelijke traditie en daaropvolgende secularisering $^{8}$ (Therborn 1995; Inglehart 1997) en waarvan de meerderheidstaal niet geworteld is in de Indo-Europese talenfamilie. In onze analyse nemen we dus die auteurs mee wier etnische oorsprong kan worden herleid tot $\mathrm{Afrika}^{9}$, Azië (inclusief Turkije), en Latijns Amerika (inclusief Mexico). De metacategorie 'schrijvers met een niet-westerse etnische achtergrond' omvat dus zowel binnenlandse etnische minderheidsauteurs (bijvoorbeeld Abdelkader Benali, een Nederlander met een Marokkaanse achtergrond, in de Volkskrant) en buitenlandse etnische minderheidsschrijvers (bijvoorbeeld Salman Rushdie, een Brit met een Indiase achtergrond, in de New

\footnotetext{
${ }^{8}$ Hoewel we de Verenigde Staten uiteraard in de analyse meenemen als westers land, realiseren we ons dat de secularisering in de VS in veel mindere mate heeft plaatsgevonden dan in de meeste Europese landen.

${ }^{9}$ African Americans en Native Americans, waarvan de voorouders al honderden jaren in de Verenigde Staten verblijven, nemen wij ook mee in deze studie. Hoewel ze - in tegenstelling tot niet-westerse etnische minderheden in Europese landen - niet meer als niet-westers aangemerkt kunnen worden, behoren ze wel tot de etnisch-raciale minderheidsgroepen.
} 
York Times) en etnische meerderheidsauteurs (bijvoorbeeld Orhan Pamuk, een Turk met ook een Turkse achtergrond, in de Süddeutsch Zeitung).

Vervolgens hebben we de geo-linguïstische banden geoperationaliseerd door het land of de regio van oorsprong van de schrijvers te coderen als voormalige koloniën en/of gastarbeiderlanden, conform de gegevens in Tabel 2. Ook hebben we de (voornaamste) taal waarin de auteur schrijft genoteerd, net als het gegeven of hij/zij woonachtig is in het land waarin het dagblad uitkomt, ten tijde van de verschijning van het artikel. Om dergelijke informatie te achterhalen hebben we zowel gedrukte- als internetbronnen gebruikt.

\section{RESULTATEN}

\section{De hoeveelheid berichtgeving over auteurs van niet-westerse afkomst}

Van de 2300 artikelen $^{10}$ die aan literatuur gewijd zijn, zijn er slechts 172 gericht op auteurs met een niet-westerse oorsprong, waarvan 33 binnenlandse en 139 buitenlandse schrijvers (33 voornamelijk Britse en Amerikaanse etnische minderheidsauteurs en 106 niet-westerse meerderheidsschijvers). Het aandeel van niet-westerse auteurs - d.w.z. het aantal auteurs van niet-westerse afkomst als een percentage van alle auteurs waar de kranten over schrijven - neemt toe van 0-2\% in 1955 tot $7-13 \%$ in 1995, een percentage dat stabiel blijft in 2005 (Tabel 3). Hetzelfde longitudinale patroon treffen we, verrassend genoeg, in alle vier de landen aan. De landen vertonen onderling weinig tot geen verschil in de dagbladaandacht voor auteurs van niet-westerse origine.

[Tabel 3 ongeveer hier]

Binnenlandse auteurs

\footnotetext{
${ }^{10}$ De verschillende journalistieke genres zijn min of meer evenredig vertegenwoordigd bij deze verdeling. Ongeveer de helft van de artikelen zijn recensies, $16 \%$ betreffen nieuws, $14 \%$ geven achtergrond verhalen en $13 \%$ zijn aankondigingen.
} 
De aandacht die dagbladen aan binnenlandse auteurs van niet-westerse etnische afkomst schenken, is in alle vier de landen beperkt (Tabel 3), waardoor het moeilijk is om conclusies te trekken over longitudinale ontwikkelingen. Het meest verrassend is wel de uiterst geringe presentie van etnische minderheidsauteurs in de Franse kranten, ondanks het aanzienlijke aandeel van minderheden in de bevolking en de linguïstische nabijheid. Ook de Duitse kranten berichten vrijwel niet over etnische minderheidsauteurs, met als enige uitzondering Imran Ayata in 2005. De Nederlandse dagbladedities en de New York Times wijdden in 1955 geen enkel artikel aan een etnische minderheidsauteur. In het geval van Nederland is dit niet zo vreemd, omdat etnische minderheden toen slechts $1,2 \%$ van de bevolking uitmaakten, maar in de VS was dat aandeel (van voornamelijk African-Americans) in 1955 al veel hoger (10\%). In 2005 is het aandeel etnische minderheden in Nederland tot meer dan 10\% gestegen, terwijl in de literaire berichtgeving dit aandeel slechts 5\% bedraagt. In de VS bedraagt het aandeel in de literaire berichtgeving dan inmiddels $11 \%$, maar dit percentage is nog steeds een stuk lager dan het aandeel van etnische minderheden in de totale bevolking (33\%). ${ }^{11}$ De getallen als zodanig geven daarmee maar een grove indicatie van de geobserveerde verschillen tussen de landen onderling.

\section{Buitenlandse auteurs}

Tussen 1955 en 1995 is het aandeel niet-westerse buitenlandse auteurs in alle vier de landen gegroeid (Tabel 3), met in 2005 ofwel een gestabiliseerd niveau (Duitsland) ofwel een afname (Frankrijk, Nederland en de VS). De verschillen over de vier ijkjaren zijn echter alleen in het geval van Frankrijk significant. Van 1975 tot 1995 zien we ook een significante groei in het aandeel niet-westerse buitenlandse auteurs in Duitse en Nederlandse dagbladen. Deze trend komt overeen met de stijgende tendens in de algehele dagbladberichtgeving over buitenlandse auteurs (Janssen 2009).

Hoewel de landen onderling aanzienlijk verschillen in het geval van alle buitenlandse auteurs (ibid.), zien we geen sterke crossnationale variatie in de dagbladaandacht voor auteurs van niet-

\footnotetext{
${ }^{11}$ Echter, waar de stijging tussen 1955 en 1995 vooral werd veroorzaakt door de aandacht voor African American auteurs, besteedt de New York Times in 2005 relatief meer aandacht aan eerste, tweede en derde generaties immigrantenschrijvers.
} 
westerse oorsprong. Dit heeft waarschijnlijk te maken met het beperkte aantal niet-westerse auteurs. Alleen voor 1995 kunnen we de conclusie trekken dat de Franse dagbladen meer aandacht geven aan buitenlandse auteurs met een niet-westerse achtergrond dan de Duitse. Dit duidt erop dat geolinguïstische banden inderdaad van invloed zijn op de aandacht voor buitenlandse literaire auteurs van niet-westerse afkomst. Frankrijk heeft immers de meeste banden met niet-westerse landen en Duitsland de minste (Tabel 2). Zoals we hieronder zullen zien, zit het verhaal echter iets ingewikkelder in elkaar.

Tenslotte blijken niet-westerse meerderheidsauteurs het grootste deel van de totale aandacht voor buitenlandse niet-westerse schrijvers voor hun rekening te nemen (Tabel 3). We constateren hier echter grote - hoewel niet significante - crossnationale verschillen, waarop we verderop in dit artikel terugkomen.

\section{De aard van berichtgeving over auteurs met een niet-westerse oorsprong}

Tabel 4 laat zien in hoeverre auteurs met een niet-westerse oorsprong een band hebben met de vier landen, en hoe die band eruit ziet.

[Tabel 4 ongeveer hier]

\section{Binnenlandse auteurs}

We zagen reeds dat - als gevolg van dekolonisatie en internationale migratie - de bevolkingssamenstelling van Frankrijk, Duitsland en Nederland etnisch diverser is geworden. Hetzelfde geldt voor de schrijverspopulatie in deze landen, waarvoor we hiervoor enig impressionistisch 'bewijs' hebben aangedragen. De berichtgeving over etnische minderheidsauteurs blijft echter relatief beperkt in alle vier de landen. De 33 etnische minderheidsschrijvers kenmerken zich door (i) sterke geo-linguïstische banden met het land, met name wat betreft taal (Tabel 4) en (ii) hun hoge opleidingsniveau (zie Appendix). ${ }^{12}$ Deze bevinding onderstreept het belang van cultureel en

\footnotetext{
${ }^{12}$ Het beroep van de vader als indicator van sociaal-economische klasse van de auteur bespreken we niet expliciet in de tekst, omdat deze gegevens niet in alle gevallen te vinden waren (zie Appendix). Echter, de
} 
linguïstisch kapitaal voor het verkrijgen van toegang tot het literaire veld, los van de eventuele ontvankelijkheid voor etnische diversiteit van de instituties binnen dit veld.

We hebben al gezien dat etnische minderheidsauteurs maar een klein aandeel hebben in de Franse kranten. Alle vier auteurs hebben een band met Frankrijk wat betreft taal. Twee etnische minderheidsauteurs hebben tevens een koloniale band: Rafael Confiant (Martinique) and Gisèle Pineau (Guadeloupe). Met uitzondering van Francoise Chandernagor studeerden deze schrijvers ook allen aan Franse universiteiten. Wat opvalt, is dat geen enkele schrijver met een arbeidsmigratie achtergrond (bijvoorbeeld Algerije) aandacht krijgt in de Franse kranten. Hoewel veel (nakomelingen van)arbeidsmigranten hun oorsprong hebben in Franse koloniën en de Franse taal beheersen, lopen zij wat betreft opleidingsniveau achter op de Franse meerderheid. De geringe ontvankelijkheid voor etnische diversiteit binnen het Franse literaire veld heeft mogelijk te maken met de sterke nadruk op cultureel kapitaal binnen dit veld, waardoor het voor etnische minderheidsschrijvers relatief moeilijk is om te voldoen aan het verwachtingspatroon van Franse uitgevers en literatuurcritici (Lay-Chenchabi 2004; Obbema 2003). Daar komt bij dat vanwege de universalistische traditie, de achtergrond van deze auteurs niet zoals in andere landen kan worden ingebracht om de verkoopwaarde te verhogen.

De Duitse kwaliteitsdagbladen doen, net als de Franse, nauwelijks verslag van eerste of volgende generatie etnische minderheidsauteurs met een arbeidsmigratie achtergrond; alleen Imran Ayata komt uit een Turks immigrantengezin. Deze minimale berichtgeving duidt erop dat het Duitse literaire veld inderdaad (nog) niet erg ontvankelijk is voor deze auteurs. Hierbij moeten we aantekenen dat ongeveer een vierde van de Turkse minderheidsauteurs, vooral de eerdere immigranten (Rösch 2006), (deels) in het Turks schrijft en boeken publiceert bij Turkse (minderheids-)uitgeverijen, wat waarschijnlijk verband houdt met het lage niveau van Duitse taalbeheersing van deze groep en de sterke oriëntatie op het thuisland bij deze groep (zie boven). Dit verkleint echter wel de kans op dagbladaandacht (zie Janssen 1997).

informatie die we wel hebben kunnen achterhalen, wijst erop dat nagenoeg alle schrijvers uit de midden of hogere sociaal-economische klassen komen. Uitzonderingen vinden we vooral onder de African American schrijvers. 
De aanwezigheid van etnische minderheidsauteurs in de Nederlandse dagbladen is tamelijk beperkt, ondanks de vermeende media hype rondom Marokkaanse auteurs (Anbeek 1999). Vier van de acht etnische minderheidsauteurs waaraan de Nederlandse kranten aandacht besteden zijn eerste of tweede generatie immigranten uit voormalige koloniën die in Nederland hoger onderwijs gevolgd hebben: Yvonne Keuls (1975) en Rogier Boon (1995), beiden van Indonesische afkomst, en Antoine de Kom (1995) en Tessa Leuwsha (2005), beiden van Surinaamse afkomst. In 2005 zien we de enige recensie van een afstammeling van Marokkaanse arbeidsmigranten, Abdelkader Benali. Dat er over auteurs die aan de voormalige koloniën gelieerd zijn eerder en meer wordt bericht dan over eerste of volgende generatie Turkse en Marokkaanse immigranten valt waarschijnlijk eveneens voor een deel terug te voeren op verschillen in taalbeheersing en opleidingsniveau (cultureel kapitaal). We zien daarnaast een toename in de aandacht voor etnische minderheidsauteurs uit gebieden die geen directe band met Nederland hebben (China en Egypte). Het lijkt erop dat het Nederlandse literaire veld iets meer open is gaan staan voor etnische diversiteit.

In het geval van de VS zien we dat Mexican-Americans de enige etnische groep zijn die niet vertegenwoordigd is in ons dagbladsteekproef, wat ook weer te maken kan hebben met het relatief lage Engelse taalbeheersing- en opleidingsniveau van deze groep. De New York Times bericht vanaf 1975 over - hoog opgeleide - African-American auteurs (bijvoorbeeld Gil Scott Heron, Shirlee Taylor Haizalip, Gloria Wade-Gayles), gevolgd door Asian-American auteurs in 1995 (bijvoorbeeld Amy Tan, Jin Ha) en een Native-American auteur in 2005 (Louise Erdrich). Deze ontwikkeling houdt gelijke tred met de veranderingen in de Amerikaanse canon sinds de vroege jaren '90. Maar hoewel het aandeel van etnische minderheden tot $30 \%$ gestegen is, is hun vertegenwoordiging in de dagbladberichtgeving veel beperkter.

\section{Buitenlandse auteurs}

De geo-linguïstische banden lijken voor Franse dagbladen belangrijker te zijn dan voor de Duitse, Nederlandse of Amerikaanse. Vanaf 1975 is ongeveer 40\% van de niet-westerse buitenlandse auteurs aan Frankrijk verbonden door middel van de taal, een koloniaal verleden, vestiging en/of arbeidsmigratie (of allemaal). De meerderheid bestaat uit Franssprekende auteurs die in Frankrijk 
gevestigd zijn maar nog steeds het burgerschap hebben van de kolonie waarin ze geboren zijn. ${ }^{13}$ Dagbladen en andere actoren in het Franse literaire veld hebben dan schrijvers uit de voormalige koloniën wellicht lang beschouwd als "too similar to be celebrated as exotic foreigners but too remote to be considered worthy of interest" (Casanova 2004: 122), maar toen Frankrijk eenmaal een minder centrale positie in het literair wereldsysteem begon in te nemen (zie boven), werden deze auteurs - in plaats Engelstalige Amerikaanse of Britse minderheidsauteurs - alsnog omarmd. ${ }^{14}$

Duitsland heeft geen koloniaal verleden en heeft voor zijn arbeidsmigratie voornamelijk uit één land geput, Turkije. Dit verklaart min of meer waarom geen van de auteurs in onze steekproeven uit 1975 en 1995 een band met Duitsland heeft, en maar twee van de 15 auteurs in 2005: Fadhil AlAzzawi, een schrijver met Irakese wortels die in Berlijn woont, en de Nobelprijs winnaar van 2006, Orhan Pamuk. De aanwezigheid van Pamuk in de Duitse - en Franse en Nederlandse - dagbladen heeft naar alle waarschijnlijkheid eerder te maken met diens internationale literaire reputatie dan met de Duits-Turkse arbeidsmigratie band. Voornamelijk Duitse en Nederlandse kranten berichten veelvuldig over niet-westerse "ster" auteurs, ${ }^{15}$ die grotendeels in de categorie "zonder banden" vallen.

Voor Nederland geldt dat tussen de 16 en 33\% van de niet-westerse auteurs aan Nederland verbonden is. In 1975 gaat één artikel (van de vier) over auteurs met een Surinaamse of Antilliaanse achtergrond in het algemeen. In 1995 en 2005 komen er in de krantenartikelen twee Antilliaanse auteurs voor (Frank Martinus Arion en Richard Piternella) en vier Surinaamse schrijvers (Albert Helman, Clark Accord, Roue Hupsel en Trefossa). Op de laatste na schrijven al deze auteurs in het

\footnotetext{
${ }^{13}$ Hieronder vallen Mohammed Dib, Noureddine Aba, Assia Djebar, Salah Guemriche, Rachid Mimouni (Algerije), Nacer Khemir (Tunesië), Sylvain Ntari Bemba (Kongo), Linda Le (Vietnam), en Louis Dalembert (Haït).

${ }^{14}$ De resultaten van ons onderzoek bevestigen het afnemende belang van Frankrijk, dat eerst een centrumpositie innam. Parijs lijkt weliswaar nog steeds als centrum voor de Franssprekende auteurs van de voormalige koloniën te fungeren, maar slechts enkele niet-westerse auteurs uit de niet gerelateerde gebieden zijn in Frankrijk gevestigd en/of schrijven in het Frans (Albert Cosserey en Marjane Satrapi. Bovendien zijn er maar een paar Franssprekende, in Partijs gevestigde auteurs van niet-westerse oorsprong, waarover in de Duitse, Nederlandse en Amerikaanse kranten bericht wordt (Rachid Mimouni en Amin Maalouf).

${ }^{15}$ Het onderzoeken van de mate van internationaal literair prestige aan de hand van verscheidene indicatoren als verkoopcijfers of aandacht van populaire media valt buiten het doel van deze studie. We hebben daarom alleen naar het aantal vertalingen gekeken aan de hand van UNESCO's Index Translationum. Uit deze analyse blijkt dat de niet-westerse schrijvers waaraan aandacht besteed wordt in Duitse kranten het meest vertaald zijn (gemiddelde $=168$ ), gevolgd door de auteurs in Nederlandse (gemiddelde=135) en Franse kranten (gemiddelde=118). De weinige niet-westerse auteurs in de New York Times zijn ook veelal "ster" auteurs (gemiddelde $=148$ ). Dit betekent echter niet dat dergelijke auteurs de steekproef domineren.
} 
Nederlands; de meeste van hen waren in het land van oorsprong gevestigd of daar naar terugverhuisd. Zoals verwacht (vergelijk Tabel 2) is de dagbladberichtgeving gewijd aan auteurs uit de vroegere koloniën minder uitgebreid dan in Frankrijk. De aandacht voor buitenlandse auteurs uit de arbeidsmigratie landen is ook minimaal. Geen enkele Marokkaanse auteur werd besproken in Nederlandse dagbladen, terwijl de berichtgeving over Orhan Pamuk en Nazim Hikmet waarschijnlijk meer te maken heeft met hun literaire reputatie dan met de band met arbeidsmigratie. Maar in vergelijking met Frankrijk - en in mindere mate Duitsland - wordt er in Nederland relatief veel aandacht besteed aan buitenlandse minderheidsauteurs, met name Britse én Amerikaanse schrijvers als Salmon Rushdie, Kanif Kureishi, Kazuo Ishiguro en Toni Morrison (zie Tabel 3). Deze Angelsaksische focus bevestigt de perifere positie van het Nederlandse literaire veld.

De band met arbeidsmigratie is ook niet aanwezig in het geval van de VS, want de New York Times heeft niet over Mexicaanse auteurs geschreven. Het geringe aantal niet-westerse buitenlandse auteurs in de New York Times onderstreept de centrale positie van Amerika in het literair wereldsysteem. Deze auteurs verblijven in Engelssprekende landen bijvoorbeeld Aubrey Menen en Kazuo Ishiguro (Verenigd Koninkrijk) of Browyn Bancroft (Australië) - of in de VS zelf (bijvoorbeeld Anita Desai (India) en Chris Abani (Nigeria). In vergelijking tot de niet-westerse auteurs in Frankrijk, is de oorsprong van deze auteurs die in de VS gevestigd zijn veel diverser, wat de centrale rol van Amerika in het literair wereldsysteem wederom bevestigt. Deze centrale rol wordt ook weerspiegeld in de aanzienlijke hoeveelheid etnische minderheidsauteurs uit de VS ${ }^{16}$ en in de VS gevestigde buitenlandse auteurs ${ }^{17}$ waarover in de Europese kranten verslag wordt gedaan.

\section{CONCLUSIES}

\footnotetext{
${ }^{16}$ Vooral in Nederland (Abraham Rodriguez, Timothy Mo, Toni Morrison en Edgardo Vega Yunque) en Duitsland (James Baldwin, Ailing Zhang, Suki Kim, Adrian Tomine, Toni Morrison, Edwidge Danticat) maar ook in Frankrijk (Gyo Fujikawa en Edwidge Danticat).

${ }^{17}$ Hieronder vallen auteurs die (voormalig) in de VS gevestigd zijn (waren), zoals Rodrigo Rey Rosa (Guatemala), Staceyann Chin (Jamaica) en Emmanuel Dongela (Kongo).
} 
De hoeveelheid dagbladberichtgeving gewijd aan literaire auteurs van niet-westerse oorsprong vertoont vanaf 1955 eenzelfde ontwikkeling voor Frankrijk, Duitsland, Nederland en de Verenigde Staten. Het aandeel van niet-westerse auteurs in het geheel van de literatuurberichtgeving nam eerst toe in alle vier de landen, vooral tussen 1975 en 1995, wat duidt op een groeiend besef van "de rest" in het Westen. Daarna, in 2005, is er sprake van een terugloop in de aandacht die dagbladen aan auteurs met een niet-westerse afkomst schenken, vooral de buitenlandse. Deze trend komt echter niet als algemeenheid naar voren uit de data die de berichtgeving over alle (westerse en niet-westerse) buitenlandse auteurs betreffen (Janssen 2009). Zou het zo kunnen zijn dat de aandacht voor etnische diversiteit een glazen plafond bereikt heeft? Meerdere auteurs hebben opgemerkt dat een aantal landen het multiculturalistisch beleid steeds meer de rug toe keren (Bloemraad, Korteweg en Yurdakul 2008). Wellicht is de afname in aandacht gerelateerd aan een verandering in het politieke klimaat van de meeste landen, met een sterkere gerichtheid op de nationale meerderheidsliteratuur als gevolg.

Als we de berichtgeving over niet-westerse binnenlandse en buitenlandse auteurs apart van elkaar bekijken, zien we wel enkele interessante - hoewel meestal niet significante - verschillen tussen de landen onderling. In vergelijking tot de dagbladen in de andere drie landen, is de berichtgeving in de Franse kranten over buitenlandse auteurs met een niet-westerse achtergrond enorm toegenomen. Dit resultaat is in lijn met de invalshoek van het literair wereldsysteem: parallel aan de erosie van Frankrijk's centrale positie, zijn de Franse dagbladen zich meer gaan oriënteren op niet-westerse buitenlandse literaturen (Janssen 2009), net zoals Franse uitgevers en cultuurbeleidsmakers (Heilbron 2008; Sapiro 2008). Deze verschuiving kan deels worden verklaard uit de geo-linguïstische banden die Frankrijk met zijn vele voormalige koloniën onderhoudt, waardoor Frankrijk het centrum is en blijft van de Franssprekende literaire wereld. Toch had ongeveer 65\% van de buitenlandse auteurs met een niet-westerse oorsprong waarover de Franse kranten in 1995 en 2005 schreven, geen specifieke band met Frankrijk. De weerstand in Frankrijk tegen globalisering à l'américaine heeft ervoor gezorgd dat er een groeiende belangstelling is voor vertaalde "perifere" buitenlandse literatuur (Sapiro 2008), een belangstelling die overigens volgens Heilbron (2008) past in de traditie van Frankrijk als een grootse literaire natie en die wellicht ook gevoed wordt door een latent gevoelde mission civilisatrice. Het is nogal verrassend, gezien de verschillen in geo-linguïstische banden en de positie die in het literair 
wereldsysteem wordt ingenomen, dat de New York Times en de Nederlandse en Duitse dagbladen elkaar nauwelijks ontlopen in hun berichtgeving over niet-westerse auteurs. Het kan zijn dat het geringe aantal onderzoekseenheden hier een rol in speelt.

Zoals verwacht is de aandacht die dagbladen aan etnische minderheidsauteurs besteden veel beperkter. Frankrijk en Duitsland hebben significante populaties van etnische minderheden, maar berichten bijna niet over etnische minderheidsauteurs. Het relatief lage taalbeheersings- en opleidingsniveau van de meeste etnische minderheidsgroepen in de vier onderzoekslanden is er ongetwijfeld voor een belangrijk deel debet aan dat betrekkelijk weinig leden van deze groepen een literaire carrière weten op bouwen. De etnische minderheidsschrijvers diè in onze krantensteekproef figureren kenmerken zich vrijwel allemaal door sterke geo-linguïstische banden met het land, met name wat betreft de taal, en door een relatief hoog opleidingsniveau. Deze bevinding onderstreept het belang van cultureel en linguïstisch kapitaal voor het verkrijgen van toegang tot het literaire veld, los van de eventuele ontvankelijkheid voor etnische diversiteit van de instituties binnen dit veld. Dat laat onverlet dat het literaire veld in zowel Frankrijk als Duitsland niet erg ontvankelijk lijkt te zijn voor etnische minderheidsauteurs. Met name het geval van Frankrijk - waar etnische minderheidsauteurs vrijwel helemaal afwezig zijn - is tamelijk intrigerend en vraagt om nader onderzoek, aangezien het dit toch niet uitsluitend kan liggen - zoals wel wordt gesteld (Lay-Chenchabi 2004; Obbema 2003) aan de gebrekkige linguïstische kwaliteiten dan wel de moeilijke verkoopbaarheid van deze schrijvers. Het lijkt erop dat Nederlandse literaire instituties - waaronder ook de dagbladen - meer open zijn gaan staan voor etnische minderheidsauteurs, hoewel de eerste en volgende generatie arbeidsmigratie minderheden achter lopen op auteurs uit de voormalige koloniën. Onze steekproef van de New York Times, ten slotte, telt meer etnische minderheidsauteurs dan alle Europese edities samen, wat in overeenstemming is met het grotere aantal etnische minderheden in het Amerikaanse literaire veld, en de grotere en ook vroegtijdigere aandacht binnen dit veld voor etnische diversiteit.

De hoeveelheid dagbladaandacht voor niet-westerse meerderheidsauteurs suggereert dat culturele globalisering in de smalle zin - de verspreiding van culturele artefacten van "the rest" richting "the West" - de grootste oorzaak is van etnische diversiteit in de berichtgeving over literatuur. Niettemin lijkt ook de invloed van international migratie te zijn toegenomen. Vanwege eerder 
genoemde redenen is het directe effect op elk nationaal literair veld relatief beperkt, met uitzondering van de VS. De toegenomen aandacht voor Amerikaanse (en Britse) etnische minderheidsauteurs in met name Nederlandse en Duitse kranten lijkt aan te tonen dat het effect van internationale migratie gemedieerd wordt door de positie van een land in het literaire wereldsysteem. Door de strijd om de canon konden deze auteurs binnen de VS groeiende erkenning verwerven, die erin uitmondde dat ze werden opgenomen in universitaire curricula en in aanmerking kwamen voor prestigieuze literatuurprijzen. In het literair wereldsysteem is de VS een steeds centralere positie in gaan nemen. Daarbij kwam bovendien de toenemende dominantie van het Engels. Beide factoren hebben ertoe bijgedragen dat auteurs zoals Toni Morrison en zelfs "non-ster" auteurs Edwidge Danticat, Ailing Zhang and Suki Kim internationaal literair prestige verwierven. Verschillende Britse etnische minderheidsauteurs, zoals Salman Rushdie, hebben vergelijkbare carrières kunnen ontwikkelen. Een dergelijke weg naar internationale literaire roem lijkt echter niet weggelegd voor de Nederlandse en Duitse etnische minderheidsauteurs en is ook minder waarschijnlijk geworden voor hun collega's in Frankrijk. Zelfs al zouden deze auteurs in hun respectieve binnenlandse literaire velden een prominente status verkrijgen, dan nog zou de kans op een internationale doorbraak gering zijn, omdat ze geen deel uitmaken van een van de Engelssprekende centra in het literair wereldsysteem en evenmin in een hypercentrale taal schrijven.

\section{Acknowledgment}

Dit onderzoek is verricht met behulp van een subsidie van de Nederlandse Organisatie voor Wetenschappelijk Onderzoek als onderdeel van het VICI-project Cultural Classifications in Transition (NWO- project 277-45-001). We zijn Sarah Corse, Gisèle Sapiro en de anonieme reviewers van Nederlandse Letterkunde erkentelijk voor hun commentaar op eerdere versies van dit artikel en voor hun suggesties voor verbetering. 


\section{REFERENCES}

Anbeek, Ton. 1999. "Fataal Succes: Over Marokkaans-Nederlandse Auteurs en hun Critici." Literatuur 16 (6):335-342.

Aynan, Asis. 2006. Who's Who van de Marokkaanse Woordkunstenaars. Passionate 2(13):610.

Benson, Rodney \& Abigail C. Saguy. 2005. "Constructing Social Problems in an Age of Globalization: a French-American Comparison." American Sociological Review 70:233-259.

Berkers, Pauwke. 2009. "Ethnic Boundaries in National Literaary Histories: Classification and of Ethnic Minority Fiction Authors in American, Dutch and German Literary History Books and Anthologies, 1978-2006". Poetics 35 (in press).

Berkers, Pauwke. 2009. "Ethnic Boundaries in American, Dutch and German National Literary Policies, 1965-2005." International Journal of Cultural Policy 15(1):33-50.

Bloemraad, Irene, Anna Korteweg \& Gökce Yurdakul. 2008."Citizenship and Immigration: Multiculturalism, Assimilation, and Challenges to the Nation-State." Annual Review of Sociology 34:153-179.

Bourdieu, Pierre. 1993. The Field of Cultural Production. Essays on Art and Literature. Cambridge: Polity Press.

Bryson, Bethany. 2005. Making Multiculturalism: Boundaries and Meaning in U.S. English Departments. Stanford, CA: Stanford University Press.

Brubaker, Rogers. 1992. Citizenship and Nationhood in France and Germany. Cambridge, MA: Harvard University Press.

Carliner, Geoffrey. 2000."The Language Ability of U.S. Immigrants: Assimilation and Cohort Effects." International Migration Review 34(1):158-182.

Casanova, Pascal. 2004. The World Republic of Letters. Cambridge, MA: Harvard University Press.

Centraal Bureau voor de Statistiek. 2008. http://statline.cbs.nl.

Chiswick, Barry R. \& Paul W. Miller. 2001. A Model of Destination-Language Acquisition: Application to Male Immigrants in Canada. Demography 38(3):391-409. 
Clausen, Lisbeth. 2003. Global News Production. Copenhagen: Copenhagen Business

School Press.

Corse, Sarah M. \& Monica D. Griffin. 1997. "Cultural Valorization and African American

Literary History: Reconstructing the Canon." Sociological Forum 12(2):173-203.

Crane, Diane. 2002. Culture and Globalization. "Theoretical Models and Emerging Trends."

Pp. 1-28 in Global Culture. Media, Arts, Policy, and Globalization, edited by D. Crane, N.

Kawashima and K. Kawasaki. London and New York: Routledge.

Crystal, David. 1997. English as a Global Language. Cambridge: Cambridge University

Press.

Darling-Wolf, Fabienne. 2008. "Getting Over Our "Illusion d'Optique": From Globalization to Mondialisation (Through French Rap)." Communication Theory 18(2):187-209.

De Swaan, Abram. 1995. "De Sociologische Studie van de Transnationale Samenleving." Amsterdams Sociologisch Tijdschrift 22/1:16-35.

De Swaan, Abram. 2001. Words of the World: The Global Language System. Cambridge: Polity Press.

Diehl, Claudia \& Michael Blohm. 2003. "Rights or Identity? Naturalization Processes Among "Labor Migrants" in Germany." International Migration Review 37(1):133-162.

Dorleijn, Gillis \& Kees (red.) 2006. De Productie van Literatuur: Het Nederlandse Literaire Veld, 1800-2000. Nijmegen: Vantilt.

Duell, Jason. 2000. "Assessing the Literary: Intellectual Boundaries in French and American Literary Studies." Pp. 94-124 in Rethinking Comparative Cultural Sociology. Repertoires of Evaluation in France and the United States, edited by M. Lamont and L. Thévenot. Cambridge: Cambridge University Press.

Dustmann, Christian. 1994. "Speaking Fluency, Writing Fluency and Earnings of Migrants." Journal of Population Economics 7:133-156.

Espenshade, Thomas J. \& Haishan Fu. 1997. An Analysis of English-Language Proficiency Among U.S. Immigrants. American Sociological Review 62:288-305.

Fetzer, Joel S. 2000. Public Attitudes toward Immigration in the United States, France, and Germany. Cambridge: Cambridge University Press. 
Fetzer, Joel S. \& J. Christopher Soper. 2005. Muslims and the State in Britain, France, and Germany. Cambridge: Cambridge University Press.

Ferree, Myra M., William A. Gamson, Jürgen Gerhards \& Dieter Rucht. 2002. Shaping Abortion Discourse: Democracy and the Public Sphere in Germany and the United States. Cambridge: Cambridge University Press.

Fiss, Peer C. \& Paul M. Hirsch. 2005. "The Discourse of Globalization: Framing and Sensemaking of an Emerging Concept." American Sociological Review 70:29-52.

Griswold, Wendy 1987. "The Fabrication of Meaning: Literary Interpretation in the United States, Great Britain and the West Indies." American Journal of Sociology 92:10771117.

Griswold, Wendy. 1992. "The Writing on the Mud Wall. Nigerian Novels and the Imaginary Village." American Sociological Review 56: 709-724.

Guillén, Mauro 2001. "Is Globalization Civilizing, Destructive or Feeble? A Critique of Five Key Debates in the Social Science Literature." Annual Review of Sociology 27: 235-260. Hargittai, Eszter \& Miguel A. Centeno. 2001. "Introduction: Defining a Global Geography." American Behavioral Scientist 44(10):1545-1560.

Hargreaves, Alec G. 1995. Immigration, 'Race' and Ethnicity in Contemporary France. New York: Routledge.

Hargreaves, Alec G. 1997. Immigration and Identity in Beur Fiction: Voices From the North African Community in France. Oxford: Berg.

Heilbron, Johan. 1999. "Towards a Sociology of Translation: Book Translations as a Cultural World-System." European Journal of Social Theory 2, 429-444.

Heilbron, Johan. 2008. "Responding to Globalization: The Development of Book Translations in France and the Netherlands." Pp. 197-197 in Beyond Descriptive Translation Studies: Investigations in Homage to Gideon Toury, edited by A. Pym, M.Shlesinger and D. Simeoni. Amsterdam: John Benjamins.

Held, David, Anthony McGrew, David Goldblatt \& Jonathan Perraton. 1999. Global transformations. Politics, Economics, Culture. Cambridge: Polity Press. 
Huggan, Graham. 2001. The Post-Colonial Exotic: Marketing the Margins. London, New York:

Routledge.

Inglehart, Ronald. 1997. Modernization and Postmodernization: Cultural, Economic, and Political

Change in 43 Societies. Princeton: Princeton University Press.

INSEE (Institut National de la Statistique et des Études Économiques). 1999. Population Census.

Jankowsky, Karen. 1997. "German Literature Contested: The 1991 Ingeborg-Bachmann-Prize Debate, "Cultural Diversity," and Emine Sevgi Özdamar." The German Quarterly 70 (3):261-276.

Janssen, Susanne. 1997. "Reviewing As Social Practice: Institutional Constraints On Critics’ Attention For Contemporary Fiction." Poetics 24:275-297.

Janssen, Susanne. forthcoming 2009. "Foreign Literatures in National Media" Arcadia. International Journal for Literary Studies 44 (2).

Janssen, Susanne, Giselinde Kuipers \& Marc Verboord. 2008. "Cultural Globalization and Arts Journalism. The International Orientation of Arts and Culture Coverage in American, Dutch, French, and German Newspapers, 1955 to 2005." American Sociological Review 73(5):719740.

Joosten, Jos. 2005. Waar Zou Spits op Doelen? Trouw, July 23, 2005, L01.

Kaufman, Jason \& Orlando Patterson. 2005. "Cross-National Cultural Diffusion: The Global Spread of Cricket." American Sociological Review 70(1):82-110.

Koopmans, Ruud, Paul Statham, Marco Giugni \& Florence Passy. 2005. Contested Citizenship: Immigration and Cultural Diversity in Europe. Minneapolis: University of Minnesota Press.

Kraidy, Marwan M. 2002. "Hybridity in Cultural Globalization." Communication Theory 3:316-339.

La Palestina, Antonio C. \& Joseph D. Straubhaar. 2005. "Multiple Proximities between Television Genres and Audiences." Gazette 67:271-288.

Lay-Chenchabi, Kathryn. 2004. "Breaking the Silence: Beur Writers Impose their Voice." Contemporary French and Francophone Studies 10(1):97-104. 
Lizardo, Omar. 2008. "Understanding the Flow of Symbolic Goods in the Global Cultural Economy." International Journal of Contemporary Sociology 45(1):13-34.

Lucassen, Jan \& Rinus Penninx. 1996. Nieuwkomers, Nakomelingen, Nederlanders: Immigranten in Nederland 1550-1993. Amsterdam: Het Spinhuis.

Malingret, Laurence. 2002. Stratégies de Traduction: Les Lettres Hispaniques en Langue Française. Arras: Artois Presses Universite.

Martin, Philip M. 1998. Germany: Reluctant Land of Immigration. Washington, D.C: American Institute for Contemporary German Studies (AICGS).

Massey, Douglas S., Joaquin Arango, Graeme Hugo, Ali Kouaouci, Adela Pellegrino \& J. Edward Taylor. 1993. "Theories of International Migration: A Review and Reappraisal." Population and Development Review 19(3):431-66.

Nagel, Joanna. 19994. "Constructing Ethnicity: Creating and Recreating Ethnic Identity and Culture." Social Problems 41(1):152-176.

Nap-Kolhoff, Elma. 2002. Turkse Auteurs in Nederland: Verkenning van Onontgonnen Gebied. Tilburg: Wetenschapswinkel Universiteit van Tilburg.

Obbema, Fokke. Allochtoon Verkoopt Niet. De Volkskrant, March 3, 2003.

Portes, Alejandro \& Rubén Rumbaut. 1996. Immigrant America: A Portrait. Berkeley: University of California Press.

Riffe, Daniel, Charles F. Aust \& Stephen R. Lacy. 1993. "The Effectiveness of Random, Consecutive Day and Constructed Week Samples in Newspaper Content Analysis". Journalism Quarterly 70: 133-139.

Rösch, Heidi. 2006. Kurzporträts und Veröffentlichung von und zu Autorinnen der deutschsprachigen Migrationsliteratur. www2.tuberlin.de/fak1/el/board.cgi?id=fadi\&action=download\&gul=36

Sapiro, Gisèle (red.) 2008. Translatio. Le marché de la traduction en France à l'heure de la mondialisation, Paris: CNRS Editions.

Sassoon, Donald. 2006. The Culture of the Europeans. From 1800 to the Present. London: 
Harper Press.

Shoemaker, Pamela A. \& Stephen D. Reese. 1996. Mediating the Message. Theories of Influences on Mass Media Content. White Plains, NY: Longman.

Statistisches Bundesamt. 2002, 2003, 2006. Bevölkerung und Erwerbstätigkeit. Statistisches Bundesamt.

Steenmeijer, Maarten.1989. De Spaanse en Spaans-Amerikaanse Literatuur in Nederland, 1946-1985. Muiderberg: Coutinho.

Tesser, Paul, Ans Merens \& Carlo van Praag. Rapportage Minderheden 1999. Den Haag: Sociaal Cultureel Planbureau.

Teraoka, Arlene A. 1997. "Multiculturalism and the Study of German Literature." Pp. 63-78 in A User's Guide to German Cultural Studies, edited by S. Denham, I. Kacandes and J. Petropoulos. Ann Arbor: The University of Michigan Press.

Therborn, Göran. 1995. European Modernity and Beyond: The Trajectory of European Societies, 1945-2000. Thousand Oaks, CA: Sage.

U.S. Bureau of the Census. 1981, 2000. Summary Files.

- 2007. Statistical Abstract of the United States. Government Printing Office.

Van Rees, Kees. 1983. "How a Literary Work Becomes a Masterpiece." Poetics 12 (4-5):397-417.

Van Rees, Kees. 1987. "How Reviewers Reach Consensus On the Value of Literary Works." Poetics 16:275-294.

Van Tubergen, Frank \& Matthijs Kalmijn. 2005. "Destination-Language Proficieny in Cross-National Perspective: A Study of Immigrant Groups in Nine Western Countries". American Journal of Sociology 110(5):1412-57.

Worbs, Susanne. 2003. The Second Generation in Germany: Between School and Labor Market. International Migration Review 37(4):1011-1038. 


\section{TABELLEN}

Tabe1 1. Achtergrond kenmerken van etnische minderheidsgroepen in Frankrijk, Duitsland, Nederland, en de Verenigde Staten.

\begin{tabular}{llll}
\hline & Frankrijk & Duitsland & Nederland \\
\hline Dominante & Niet-westerse & Niet-westerse & Niet-westerse etnische \\
Terminologie & buitenlanders & buitenlanders & minderheden \\
(Operationalisering) & & (Turkse minderheid) & \\
\hline
\end{tabular}

Omvang (\% van de

totale populatie $)^{1}$

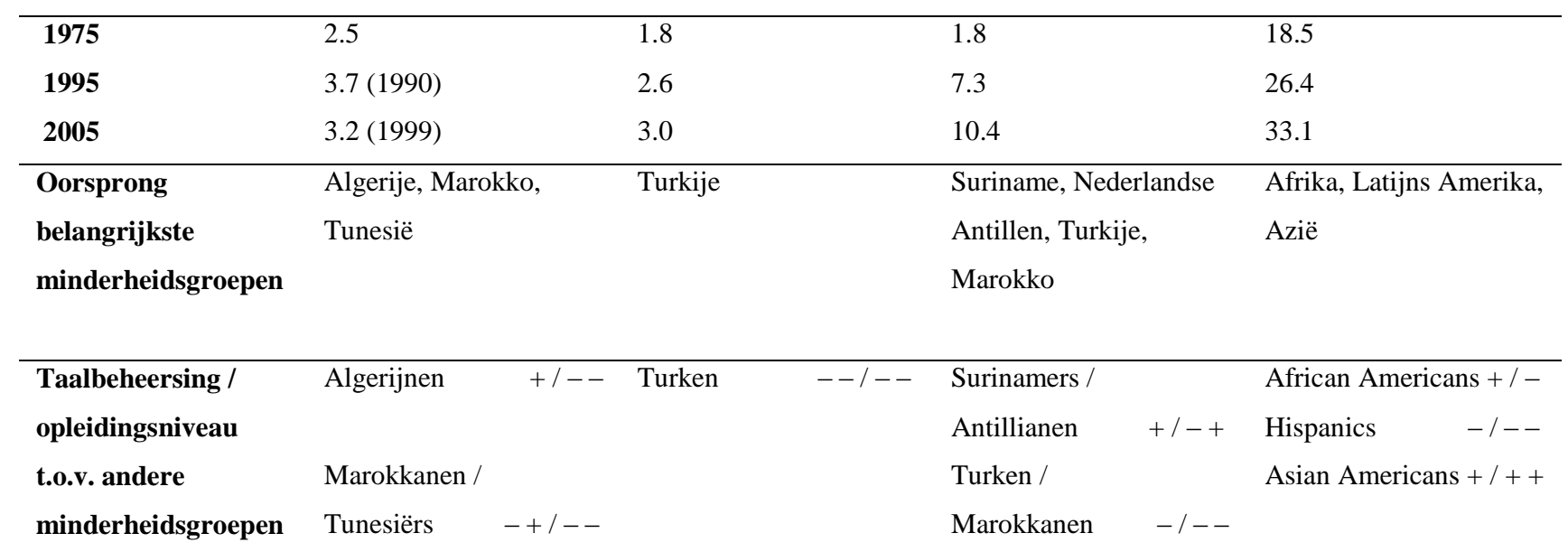

Bronnen: Frankrijk: Hargreaves (1995), INSEE (1999); Duitsland: Statistisches Bundesamt (2002, 2003, 2006);

Nederland: Centraal Bureau voor de Statistiek (2008); Verenigde Staten: U.S. Bureau of the Census (1981,

2000, 2007).

1 We hebben 1955 uit de analyse gelaten aangezien er voor dat jaar geen vergelijkbare data beschikbaar zijn.

${ }^{2}$ Mensen die zichzelf classificeren als "Black or African American, Hispanic or Latino, Asian or Pacific Islander and American Indian or Alaska Native." 
Tabel 2. Geo-linguïstische banden van Frankrijk, Duitsland, Nederland en de Verenigde Staten met niet-westerse landen

\begin{tabular}{llll}
\hline & Koloniale Banden & Taalkundige Banden & Arbeidsmigratie Banden \\
\hline Frankrijk & Marokko, Algerije, Tunesië & Marokko, Algerije, Tunesië & Marokko, Algerije, Tunesië \\
& Senegal, Gambia, Niger, Mali, & Senegal, Gambia, Niger, Mali, & Senegal, Gambia, Niger, Mali, \\
& Guinee, Ivoorkust, Burkina & Guinee, Ivoorkust, Burkina & Guinee, Ivoorkust, Burkina \\
& Faso, Benin, Gabon, & Faso, Benin, Gabon, & Faso, Benin, Gabon, \\
& Democratische Republiek & Democratische Republiek & Democratische Republiek \\
& Congo, Centraal-Afrikaanse & Congo, Centraal-Afrikaanse & Congo, Centraal-Afrikaanse \\
& Republiek, Tsjaad & Republiek, Tsjaad & Republiek, Tsjaad \\
& Franse Caraïben* & & \\
& Vietnam, Laos, Cambodja & & \\
\hline Duitsland & & & Turkije \\
\hline Nederland & Suriname, Nederlandse & Suriname, Nederlandse Antillen & Turkije, Marokko \\
& Antillen, Indonesië & Voormalige Britse koloniën & Mexico \\
\hline VS & & (e.g. Ghana, Nigeria) & \\
& &
\end{tabular}

* De Franse overzeese regio's (DOM-TOM), zoals Martinique, Guadeloupe en Frans Guyana, zijn officiële departementen van Frankrijk en worden daarom niet meegerekend. 
Tabel 3. Hoeveelheid schrijvers met een niet-westerse etnische achtergrond besproken in dagbladen (totaal, binnenlands en buitenlands) per land en jaar

\begin{tabular}{|c|c|c|c|c|c|}
\hline & & 1955 & 1975 & 1995 & 2005 \\
\hline \multirow[t]{5}{*}{ Frankrijk } & Totaal & $2 \%$ & $4 \%$ & $13 \%$ & $11 \%$ \\
\hline & Binnenlands & $0 \%(0)$ & $0 \%(0)$ & $2.4 \%(3)$ & $1.0 \%(1)$ \\
\hline & Buitenlands & $8.3 \%(1)$ & $9.1 \%(5)$ & $24.8 \%(26)$ & $18.1 \%(25)$ \\
\hline & - etnische minderheid & (0) & (1) & (4) & (1) \\
\hline & - niet-westerse meerderheid & (1) & (4) & (23) & (24) \\
\hline \multirow[t]{5}{*}{ Duitsland } & Totaal & $0 \%$ & $2 \%$ & $7 \%$ & $8 \%$ \\
\hline & Binnenlands & $0 \%(0)$ & $0 \%(0)$ & $0 \%(0)$ & $1.4 \%(1)$ \\
\hline & Buitenlands & $0 \%(0)$ & $3.9 \%(3)$ & $12.1 \%(15)$ & $12.1 \%(15)$ \\
\hline & - etnische minderheid & (0) & (1) & (4) & (4) \\
\hline & - niet-westerse meerderheid & (0) & (2) & (11) & (11) \\
\hline \multirow[t]{5}{*}{ Nederland } & Totaal & $0 \%$ & $6 \%$ & $12 \%$ & $9 \%$ \\
\hline & Binnenlands & $0 \%(0)$ & $3.2 \%(1)$ & $3.1 \%(2)$ & $5.1 \%(5)$ \\
\hline & Buitenlands & $0 \%(0)$ & $6.8 \%(4)$ & $18.4 \%(19)$ & $12.5 \%(15)$ \\
\hline & - etnische minderheid & $(0)$ & $(0)$ & (9) & (6) \\
\hline & - niet-westerse meerderheid & $(0)$ & (4) & $(10)$ & (9) \\
\hline \multirow[t]{6}{*}{ VS } & Totaal & $1 \%$ & $3 \%$ & $11 \%$ & $11 \%$ \\
\hline & Binnenlands & $0 \%(0)$ & $4.2 \%(3)$ & $9.3 \%(8)$ & $10.8 \%(9)$ \\
\hline & - excl. African en Native Americans & (0) & $(0)$ & (3) & (6) \\
\hline & Buitenlands & $1.6 \%(1)$ & $0 \%(0)$ & $13.2 \%(5)$ & $10.5 \%(4)$ \\
\hline & - etnische minderheid & (1) & $(0)$ & (0) & (2) \\
\hline & - niet-westerse meerderheid & (0) & $(0)$ & (5) & (2) \\
\hline
\end{tabular}

Noot: totaal is een percentage van de totale steekproef van schrijvers; binnenlands is een percentage van alle binnenlandse auteurs; buitenlands is een percentage van alle buitenlandse schrijvers 
Tabel 4. Banden tussen land van het dagblad en van de besproken auteurs met een niet-westerse etnische achtergrond (binnenlands en buitenlands), 1955-2005 (N=172)

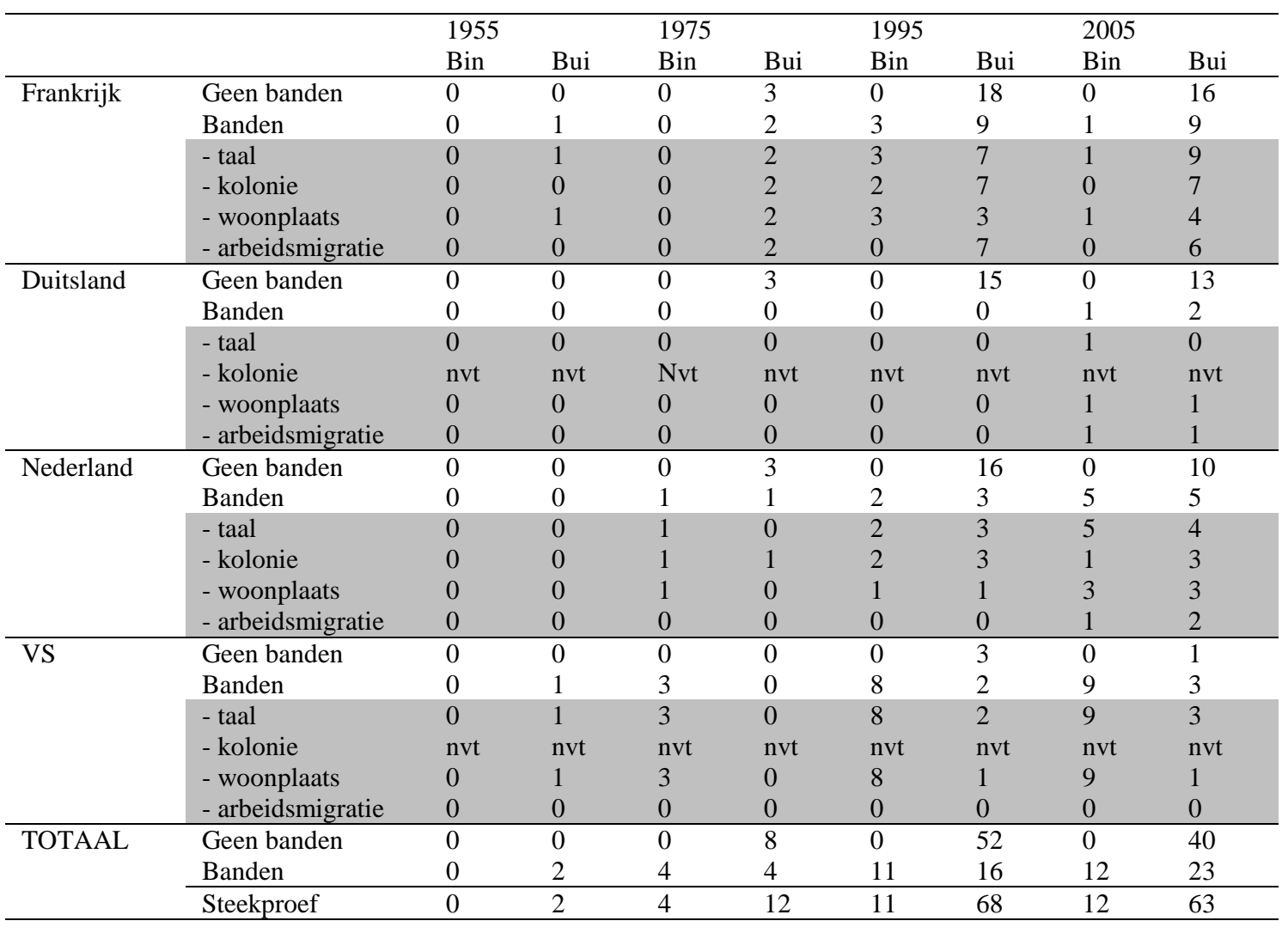

Noot: Alle cijfers zijn absolute getallen. Grijze cellen geven de banden per subcategorie weer (taal, kolonie, woonplaats en arbeidsmigratie); in tegenstelling tot de hoofdcategorieën (geen banden; banden), kunnen deze doublures bevatten aangezien schrijvers meerdere banden met het land van het dagblad kunnen hebben. 
Appendix. Achtergrondkenmerken van de besproken etnische minderheidsauteurs per jaar en land.

\begin{tabular}{|c|c|c|c|c|c|c|}
\hline Jaar & Land & Auteur & $\begin{array}{l}\text { Etnische } \\
\text { Achtergrond }\end{array}$ & $\begin{array}{l}\text { Immigrant } \\
\text { Generatiie }\end{array}$ & $\begin{array}{l}\text { Beroep vader } \\
\text { (moeder) }\end{array}$ & $\begin{array}{l}\text { Opleiding } \\
\text { (land) }\end{array}$ \\
\hline 1955 & - & - & - & - & - & - \\
\hline 1975 & NL & Keuls, Yvonne & Indonesisch & 2 & Onderwijzer & Kweekschool (NL) \\
\hline 1975 & VS & Scott-Heron, Gil & African-American & - & Atleet & Universiteit (VS) \\
\hline 1975 & VS & Killens, John Oliver & African-American & - & & Universiteit (VS) \\
\hline 1975 & VS & Bradley, David & African-American & - & Predikant & Universiteit (VS) \\
\hline 1995 & FR & Chandernagor, Françoise & Indiaas & $?$ & & \\
\hline 1995 & FR & Pineau, Gisèle & Frans Caribisch & - & & Universiteit (FR) \\
\hline 1995 & FR & Confiant, Rafael & Frans Caribisch & - & & Universiteit (FR) \\
\hline 1995 & NL & Boon, Rogier & Indonesisch & 1 & & Kunstacademie (NL) \\
\hline 1995 & NL & Kom, Antoine A.R. de & Surinaams & 2 & $?$ & Universiteit (NL) \\
\hline 1995 & VS & Haizlip, Shirlee Taylor & African-American & - & Predikant & Universiteit (VS) \\
\hline 1995 & VS & Johnson, Helene & African-American & - & (Huisvrouw) & $?$ \\
\hline 1995 & VS & Orlandersmith, Dael & African-American & - & Geen vader, arm & Universiteit (VS) \\
\hline 1995 & VS & Wade-Gayles, Gloria & African-American & - & & Universiteit (VS) \\
\hline 1995 & VS & Woodson, Jacqueline & African-American & - & & Universiteit (VS) \\
\hline 1995 & VS & Mochizuki, Ken & Asian-American & 3 & Sociaal werker & Universiteit (VS) \\
\hline 1995 & VS & Tan, Amy & Asian-American & 2 & Predikant & Universiteit (VS) \\
\hline 1995 & VS & Tilly, Meg & Asian-American & 3 & (Onderwijzer) & $?(\mathrm{VS})$ \\
\hline 2005 & FR & Ladjali, Cecile & Iraans & 2 & & Universiteit (FR) \\
\hline 2005 & DU & Ayata, Imran & Turks & 2 & & Universiteit (DU) \\
\hline 2005 & NL & Leuwsha, Tessa & Surinaams & 2 & & Universiteit (NL) \\
\hline 2005 & NL & Benali, Abdelkader & Marokkaans & 1 & Slager & Universiteit (NL) \\
\hline 2005 & NL & Nasr, Ramsey & Palestijns & 2 & & Theater school (VS) \\
\hline 2005 & NL & Wang, Lulu & Chinees & 1 & Politicus & Universiteit $(\mathrm{CH})$ \\
\hline 2005 & NL & Wang, Lulu & Chinees & 1 & Politicus & Universiteit $(\mathrm{CH})$ \\
\hline 2005 & VS & Williams, Maiya & African-American & - & Entomoloog & Universiteit (VS) \\
\hline 2005 & VS & Danticat, Edwidge & Black & 1 & Taxi chauffeur & Universiteit (VS) \\
\hline 2005 & VS & Jin, Ha & Asian-American & 1 & Militair officier & Universiteit (VS) \\
\hline 2005 & VS & Jin, Ha & Asian-American & 1 & Militair officier & Universiteit (VS) \\
\hline 2005 & VS & Revoyr, Nina & Asian-American & 2 & & Universiteit (VS) \\
\hline 2005 & VS & Lahiri, Jhumpa & Asian-American & 2 & Bibliothecaris & Universiteit (VS) \\
\hline 2005 & VS & Hosseini, Khaled & Asian-American & 1 & Diplomaat & Universiteit (VS) \\
\hline 2005 & VS & Erdrich, Louise & Native-American & - & Onderwijzer & Universiteit (VS) \\
\hline 2005 & VS & Erdrich, Louise & Native-American & - & Onderwijzer & Universiteit (VS) \\
\hline
\end{tabular}

FR=Frankrijk; DU=Duitsland; NL=Nederland; VS=Verenigde Staten; China 